\title{
Artikel
}

\section{Nieuwe planningsbeperkingen in de Vlaamse erf- en schenkbelasting tegen de achtergrond van vermogensongelijkheid}

Mr. dr. K.M.L.L. van de Ven*

\section{Inleiding}

Het effect van erfenissen en schenkingen op de vermogensongelijkheid staat al enige tijd in de belangstelling door het boek Capital in the tmenty-first century van de Franse econoom Piketty. ${ }^{1}$ Piketty betoogt dat overdrachten tussen generaties voor een toenemende vermogensongelijkheid zorgen.

In Nederland is in december 2019 een notitie van het Centraal Planbureau (CPB) verschenen met de titel 'Effect van erfenissen en schenkingen op vermogensongelijkheid en de rol van belastingen'. In de notitie is gebruik gemaakt van nieuwe data van het Centraal Bureau voor de Statistiek (CBS), afkomstig uit de periode 2007-2015.

De in de notitie uitgesproken verwachting dat de vermogens van huishoudens die een erfenis of schenking hebben ontvangen, zich gunstiger ontwikkelen dan de vermogens van huishoudens die niets hebben ontvangen of juist hebben gegeven, wordt voor de periode 2007-2015 negatief beantwoord: de vermogensongelijkheid is in die periode ongeveer gelijk gebleven. Daarbij speelt de daling van de woningprijzen een belangrijke rol.

Mw. mr. dr. K.M.L.L. van de Ven is docent belastingrecht aan de Universiteit Maastricht en tevens eigenaar Athena Advies en Praktijk.

1. T. Piketty, Capital in the twenty-first century, Cambridge, MA: Harvard University Press 2014
Planningstechnieken om belasting te besparen worden, mede als gevolg van het hiervoor genoemde boek van Piketty, niet alleen in Nederland, maar ook in België kritisch bekeken. De kritische blik richt zich niet alleen op besparing van vennootschapsbelasting ${ }^{2}$ en inkomstenbelasting, maar ook op besparing van schenk- en erfbelasting.

In de verkiezingsprogramma's 2021 van $\mathrm{D} 66^{3}$ en GroenLinks ${ }^{4}$ bijvoorbeeld staat dat vermogensongelijkheid wordt doorgegeven van generatie op generatie en dat erfenissen en schenkingen niet onevenredig bij mensen terecht moeten komen die al relatief welvarend zijn. D66 wil de tarieven erf- en schenkbelasting verhogen, en GroenLinks wil de erfbelasting afschaffen voor 'gewone' huishoudens met een gemiddelde erfenis. 'Grote' erfenissen zouden juist zwaarder moeten worden belast.

Het CDA wil daarentegen de toch regelmatig ter discussie gestelde bedrijfsopvolgingsfaciliteiten voor familiebedrijven behouden en vereenvoudigen. ${ }^{5}$ Forum voor Democratie vindt de schenk- en erfbelasting onrechtvaardig en wil deze afschaffen. ${ }^{6}$

In deze bijdrage ga ik in op met ingang van 1 juli 2021 van toepassing zijnde nieuwe Vlaamse fiscale planningsbeperkingen. ${ }^{7}$ Daarbij leg ik, waar relevant, een link

2. Zie onder meer de uitkomsten voor de vennootschapsbelasting van 11 juni 2021 van de top van de G7 in het Verenigd Koninkrijk. Zie D66.nl/verkiezingsprogramma 2021, 'Een nieuw begin'.

4. Zie Groenlinks.nl/verkiezingsprogramma 2021, 'Tijd voor nieuw realis$\mathrm{me}^{\prime}$.

5. Cda.nl/verkiezingsprogramma 2021-2025, 'Nu doorpakken'.

6. Fvd.nl/verkiezingsprogramma 2021-2025, 'Stem Nederland terug'.

7. Decreet van 19 maart 2021 tot wijziging van de Vlaamse Codex Fiscaliteit van 13 december 2013, wat betreft de tariefverlaging voor non- 
naar de Nederlandse regelgeving. Ook sta ik kort stil bij een eerdere - in 2020 - door de Belgische federale wetgever getroffen maatregel, die als doel had de schenking via een buitenlandse notaris onaantrekkelijk te maken.

\section{Een eerdere beperking en het vervolg daarop}

\subsection{Sluiten 'kaasroute'}

In België heeft de kritische blik vanuit de samenleving en politiek ertoe geleid dat met ingang van 15 december 2020 een federale fiscale wetswijziging is doorgevoerd, die ervoor heeft gezorgd dat de al jaren veelgebruikte 'kaasroute' onaantrekkelijk is geworden. De schenking van roerende goederen die is verricht voor een buitenlandse (vaak een Nederlandse of Zwitserse) notaris is met ingang van die datum in België onderworpen aan schenkbelasting. ${ }^{8}$ Tot die datum was het via deze kaasroute mogelijk om een schenking te doen van roerende goederen die, omwille van de daaraan gekoppelde voorwaarden, ${ }^{9}$ notarieel werd vastgelegd, zonder dat de begiftigde in België daarover schenkbelasting in de vorm van registratierechten was verschuldigd.

Schenken zonder schenkbelasting verschuldigd te zijn is na deze wetswijziging in alle gewesten van België nog altijd mogelijk. Voor de hand- en bankgift is namelijk geen registratie vereist. Bovendien kan de schenking van een geldbedrag of een effectenrekening door middel van een onderhandse 'pacte adjointe' nog altijd worden voorzien van nadere voorwaarden. Het is dus niet zo dat de federale wetgever de belastingvrije handgift onoorbaar vindt. Wat hij met de in december 2020 in werking getreden wetgeving uitsluitend heeft willen doen, is het poortje via de buitenlandse - Nederlandse of Zwitserse - notaris sluiten. De wetgever vond gebruikmaken van dat poortje onoorbaar, met name omdat die weg niet voor iedere rijksinwoner was weggelegd.

\subsection{De driejarenregeling}

Buiten het feit dat een notarieel vastgelegde schenking van roerende goederen de mogelijkheid biedt om in die akte voorwaarden, zoals een recht van vruchtgebruik, op te nemen, geeft de akte ook dwingend bewijs van de datum van de schenking. Zoals in Nederland schenkingen die zijn gedaan binnen een termijn van 180 dagen voor het overlijden ingevolge artikel 12 lid 1 van de Successiewet 1956 (SW 1956) geacht worden krachtens erfrecht te zijn verkregen, bestaat in het Vlaams Gewest een vergelijkbare regeling waarin een termijn van drie jaar is opgenomen: artikel 2.7.1.0.5 van de Vlaamse Codex Fiscaliteit (VCF). Deze termijn geldt specifiek voor schenkingen van roerende goederen die niet zijn

profit en non-profit schenkingen, en de invoering van de vriendenerfenis, Parl. St. VI. Parl., 2020-21, 613/1,3-4

8. Zie K.M.L.L.van de Ven, Giften en woonplaats, een Belgische federale wetswijziging, TE 2021, afl. 1, p. 1-6.

9. Zoals het voorbehouden recht van vruchtgebruik. geregistreerd en waar dus geen schenkbelasting in de vorm van registratierechten over is verschuldigd.

In het initiële wetsontwerp ${ }^{10}$ was een verlenging van de termijn van drie naar vier jaar opgenomen, met als argument dat mensen daardoor zouden worden aangemoedigd te kiezen voor een geregistreerde schenking. De bedoelde verlenging zou ingaan op 1 juli 2021 en zag op schenkingen die vanaf die datum zouden worden gedaan. De Vlaamse decreetgever heeft echter, na het federaal sluiten van de kaasroute, ervoor gekozen deze periode niet te verlengen; zij is beperkt gebleven tot drie jaar na de schenking.

Kiezen rijksinwoners in Vlaanderen voor de belastingvrije hand- of bankgift, dan worden de begiftigden bij het overlijden van de schenker binnen deze 'verdachte periode' van drie jaar geconfronteerd met erfbelasting. Wordt de schenking alsnog binnen die periodezelfs een dag voor het overlijdengeregistreerd, dan is de regeling van artikel 2.7.1.0.5 VCF niet van toepassing. De schenking wordt dan belast met schenkbelasting en niet meegenomen in het saldo van de nalatenschap. Is de verkrijger iemand in de rechte lijn of de partner, dan bedraagt het proportionele tarief 3\%. Alle andere verkrijgers worden over het bedrag van de schenking belast tegen het proportionele tarief van $7 \% .^{11}$

\section{Het duolegaat}

Het duolegaat is in het Vlaams Gewest een veelgebruikte planningstechniek, waarbij via een legaat in een testament zowel een goed doel als familie of vrienden worden begunstigd.

Het legaat aan het goede doel ${ }^{12}$ wordt belast tegen een laag proportioneel tarief erfbelasting van $8,5 \%$.

De erfbelastingtarieven die van toepassing zijn bij verkrijging door familie in de eerste graad en door verdere verwanten en derden zijn (veel) hoger. Zo gelden tussen verwanten in de rechte lijn en partners tarieven van (tot $€ 50.000) 3 \%$,(tussen $€ 50.000$ en $€ 250.000) 9 \%$ en (boven $€ 250.000)$ 27\%. Voor verkrijgingen tussen broers en zusters, maar ook voor verkrijgingen door derden gelden tarieven van $25 \%$ tot $55 \%$. $^{13}$

Een duolegaat wordt/werd meestal gebruikt door personen die geen partner en afstammelingen hebben in

10. Voorontwerp van Decreet van 19 maart 2021

11. Art. 2.8.4.1.1 §2 VCF

12. In het Belgische systeem staan meerdere rechtsvormen ter beschikking voor organisaties die een belangeloos doel nastreven. Zo kent men de 'vereniging zonder winstoogmerk' (VZW), de 'internationale vereniging zonder winstoogmerk' (IVZW) en de zogeheten 'stichting van openbaar nut' (SON). De (I)VZW en SON mogen economische activiteiten uitoefenen. Maar er mag door deze organisaties niet met een winstoogmerk worden gehandeld; winst mag niet het doel zijn van de rechtsvorm. Evenals dat in Nederland geldt voor de algemeen nut beogende instelling (ANBI) (art. 5b AWR), zijn commerciële activiteiten wel toegestaan, zolang de daarmee behaalde winsten worden aangewend voor het belangeloze doel.

13. Broers en zussen: (tot $€$ 35.000) $25 \%$,(tussen $€ 35.000$ en $€ 75.000$ ) $30 \%$ en (boven $€ 75.000$ ) 55\%. Derden: (tot $€ 35.000) 25 \%$, (tussen $€ 35.000$ en $€ 75.000$ ) $45 \%$ en (boven $€ 75.000) 55 \%$. 
1. Belastbare grondslag:
a. Algemeen legaat aan VZW

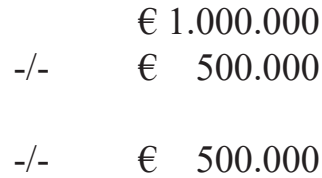
b. Bijzonder legaat aan neven en nichten
c. Gebruteerde erfbelasting over het bijzondere legaat $€ 578.889$, maar beperkt tot $€ 500.000^{1}$

2. Berekening erfbelasting verschuldigd door VZW en neven/nichten:
a. Neven en nichten worden belast over $€ 1.000 .000^{2}$ tegen het progressieve tarief
$€ 535.000$
b. VZW0\%-tarief ${ }^{3}$

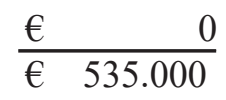

De VZW houdt in dit voorbeeld van het algemeen legaat van $€ 1.000 .000$ een nettobedrag over van -/$€ 35.500$ :

- Algemeen legaat VZW

- Bijzonder legaat neven en nichten

- Verschuldigde erfbelasting VZW

- Erfbelasting neven en nichten

\begin{tabular}{|c|c|c|}
\hline \multirow{3}{*}{$-/-$} & \multicolumn{2}{|c|}{$€ 1.000 .000$} \\
\hline & $€$ & 500.000 \\
\hline & & \\
\hline & & 535.000 \\
\hline & & \\
\hline
\end{tabular}

1. Beperkt tot het legaat aan de VZW (art. 2.7.3.2.15, 1e VCF, zoals ingevoerd bij art. 2 Decreet van 19 maart 2021).

2. Dit is het bedrag van het bijzonder legaat van $€ 500.000$ verhoogd met de daarover verschuldigde belasting van $€ 500.000$.

3. Nieuwe tarief vanaf 1 juli 2021, art. 2.7.4.2.1 VCF.

de rechte lijn, waardoor hun erfgenamen steeds in de hoge tarieven terechtkomen. De techniek van het duolegaat bestaat erin dat een deel van het vermogen wordt nagelaten aan een goed doel, op voorwaarde dat dit goede doel een deel van zijn verkriiging doorgeeft aan een vriend of familielid van de erflater, én bovendien alle erfbelasting, dus ook die van de vriend of het familielid, voor zijn rekening neemt. De berekening zat dan zo in elkaar dat het goede doel na voldoening van het eigen deel aan erfbelasting ter hoogte van $8,5 \%$, vermeerderd met de door de derde verkrijger verschuldigde erfbelasting, nog een bedrag overhield dat kon worden aangewend voor het goede doel.

Bij Decreet van 19 maart 2021 is een nieuwe berekeningsformule ${ }^{14}$ ingevoerd, die tot effect heeft dat wanneer op de vorenbedoelde wijze gebruik is gemaakt van het duolegaat, er geen enkel voordeel meer overblijft voor het goede doel. Deze berekening houdt in dat de door de verre verwanten verschuldigde erfbelasting wordt gebruteerd tegen het marginale tarief dat op hun verkriiging van toepassing is. Dat gebruteerde erfbelastingbedrag wordt vervolgens in mindering gebracht op de verkrijging van de goeddoelenorganisatie, hetgeen uiteindelijk kan leiden tot een negatieve verkrijging voor de organisatie. Die zal om die reden verwerpen.

14. Art. 2.7.3.2.15 VCF

15. Decreet van 19 maart 2021 tot wijziging van de Vlaamse Codex Fiscaliteit van 13 december 2013, wat betreft de tariefverlaging voor nonprofit en non-profit schenkingen, en de invoering van de vriendenerfenis, Parl. St. VI. Parl., 2020-21, 613/1,3-4.
In het Decreet is het volgende voorbeeld ${ }^{15}$ uitgewerkt. Een algemeen legaat ${ }^{16}$ aan een goeddoelinstelling, een VZW, onder de last om $50 \%$ vrij van erfbelasting uit te keren aan de neven en nichten van de erflater. De berekening van de verschuldigde erfbelasting bij een overlijden na 30 juni 2021 geschiedt in twee stappen (zie figuur 1).

Om de goeddoelorganisaties uiteindelijk niet de dupe te laten worden van deze wetswijziging heeft de Vlaamse decreetgever ter compensatie het tarief dat deze instellingen over schenkingen en erfrechtelijke verkrijgingen verschuldigd zijn vanaf 1 juli 2021 verlaagd naar $0 \% .{ }^{17}$ In zoverre worden deze organisaties fiscaal voortaan op dezelfde wijze behandeld als de Nederlandse ANBI en de sociaal belang behartigende instelling (SBBI).$^{18}$

15. Decreet van 19 maart 2021 tot wijziging van de Vlaamse Codex Fiscaliteit van 13 december 2013, wat betreft de tariefverlaging voor nonprofit en non-profit schenkingen, en de invoering van de vriendenerfenis, Parl. St. VI. Parl., 2020-21, 613/1,3-4.

16. Het Belgische algemeen legaat is de uiterste wilsbeschikking waarbij de erflater aan een of meer personen de algemeenheid van goederen geeft die hij bij zijn overlijden zal nalaten (art. 1003 Belgisch BW). Het algemeen legaat is de tegenhanger van de Nederlandse erfstelling.

17. Art. 2.7.4.2.1 VCF.

18. Zie art. 32 lid 1 onder 3, 8 en 9 en 33 onder 4 en 13 SW 1956. Ook voor verkrijgingen door een steunstichting SBBI is het tarief van $0 \%$ van toepassing. 


\section{Introductie van de 'vriendenerfenis'}

De reden om via een duolegaat een verre verwant of een goede vriend iets na te laten, was dat deze op die manier niet geconfronteerd werd met een, in absolute zin, zwaarbelaste verkrijging. Gelet op een samenleving waarin een traditionele gezinssituatie steeds vaker plaatsmaakt voor andere relatievormen, heeft de Vlaamse fiscale wetgever reeds met ingang van 1 september 2018 een tariefsverlaging ingevoerd voor verkrijgingen van derden-niet-verwanten en voor die van broers en zusters. Tot die tijd bedroegen de voor hen hiervoor vermelde toepasselijke tarieven erfbelasting: $45 \%, 55 \%$ en $65 \%$. De verkriigingen door broers en zusters werden belast tegen de tarieven van $30 \%, 55 \%$ en $65 \%$.

In het Decreet van 19 maart 2021 heeft de Vlaamse decreetgever een verlaging van het erfbelastingtarief ingevoerd van $25 \%$ naar $3 \%$ voor verkrijgers in de hiervoor genoemde categorieën over een maximumbedrag ter hoogte van $€ 15.000 .{ }^{19} \mathrm{Zij}$ krijgen deze vermindering in hun hoedanigheid vanzogenoemde 'beste vriend'. Deze verkrijging kan worden gespreid over meerdere 'beste vrienden', maar blijft beperkt tot een bedrag van $€ 15.000$ totaal.

Degenen die verkrijgen, moeten een natuurlijk persoon zijn, behorende tot de categorie broers/zusters of nietverwanten. Verdere voorwaarden zijn:

- De erflater heeft deze personen in een testament aangewezen als personen die voor deze vermindering in aanmerking komen. Ze moeten op 'ondubbelzinnige wijze' aangewezen worden als degenen die de toepassing van de vermindering mogen vragen. ${ }^{20}$ Het is niet verplicht de angeduide natuurlijke personen met naam te noemen, zolang de aanduiding maar ondubbelzinnig is en duidelijk uit het testament blijkt wie wordt bedoeld. Een affectieve band tussen de erflater en de bedoelde personen is niet vereist.

- De benoeming moet zijn neergelegd in een authentiek testament (zie par. 5 hierna).

- Om de vermindering te kunnen krijgen, moet in de angifte erfbelasting daarop uitdrukkelijk een beroep worden gedaan, onder vermelding van de namen van de betrokken personen. ${ }^{21}$

Met name het feit dat de voorwaarde voor de 'beste vriend' opgenomen moet worden in een authentiek testament, doet de vraag rijzen in hoeverre de nieuwe regeling in de praktijk zal worden gebruikt. Het is in België namelijk mogelijk om rechtsgeldig een onderhands testament te maken, en in de praktijk blijkt dat mensen van deze wijze van vastleggen nog altijd gebruik maken. Dat gebeurt ook wel in samenspraak met de notaris in situaties waarin het na te laten vermogen niet erg groot is. Het op die wijze testateren kan een aardige kostenbesparing betekenen in vergelijking met de situatie dat de testateur een notarieel verleden authentiek testament moet laten opstellen.

In paragraaf 5 volgt een korte uiteenzetting over de verschillende testamentsoorten.

\section{Soorten testamenten - vormvoorschriften}

Er bestaan in België drie soorten testamenten:

1. het notarieel (ook openbaar of authentiek genoemd) testament; artikel 971 Belgisch BW. Het door de notaris uitgewerkte testament wordt door hem voorgelezen en in het bijzijn van getuigen getekend;

2. het onderhandse testament; artikel 970 Belgisch BW. Dit testament moet door de erflater eigenhandig zijn geschreven, gedagtekend en ondertekend. Verdere formaliteiten zijn aan dit testament niet verbonden;

3. het internationale testament; artikel 969 Belgisch BW. Deze testamentsoort wordt gebruikt in een internationale context, waarbij de testateur verspreid over meerdere landen bezittingen heeft, of wanneer de testateur een andere nationaliteit bezit dan de Belgische. Dit testament wordt door een notaris uitgewerkt, voorgelezen en in het bijzijn van getuigen getekend.

Wat betreft de getuigen die vereist zijn ingeval de Belgische notaris een testament verlijdt: dat zijn twee personen van buiten het kantoor van de betreffende notaris, die van tevoren zijn verzocht op het angegeven tijdstip te verschijnen. De aanwezigheid van getuigen moet bevorderen dat de notaris zich ervan overtuigd heeft dat de testateur in volle bewustzijn zijn eigen wil heeft verklaard.

De nadere verschillen van de genoemde testamentsoorten komen naar voren bij het openen van het testament. Zo zal de notaris van een handgeschreven testament een proces-verbaal maken, waarin ook wordt vermeld wat de staat van het testament is. Dit proces-verbaal wordt tezamen met het testament zelf als een minuutakte opgenomen. Ditzelfde (deze procedure) geldt ook voor het internationale testament. In geval van een authentiek testament is deze procedure niet nodig. 


\section{Ter vergelijking: de Nederlandse verkrijging vrij van recht}

Ingevolge artikel $36 \mathrm{SW} 1956$ is de verkrijger belastingplichtige, hetgeen inhoudt dat hij de over zijn verkrijging verschuldigde belasting voor zijn rekening moet nemen. In een testament kan worden bepaald dat een erfrechtelijke verkrijging vrij van recht is. Meestal betreft het een legaat vrij van recht. De legataris heeft daardoor recht op een zodanige prestatie ten laste van andere verkriigers dat hij na de voldoening van de door hem verschuldigde erfbelasting de waarde van hetgeen aan hem is gelegateerd, overhoudt.

Het bovenstaande was althans de situatie tot 1 januari 2006. Tot die datum bepaalde artikel 5 lid 8 (oud) SW 1956 dat het voordeel van de verkrijging vrij van recht bestond uit hetgeen hem was toegekend, verhoogd met het daarover verschuldigde belastingbedrag. Het bedrag van de verkrijging werd slechts één keer gebruteerd met het bedrag dat de verkrijger zelf aan belasting had moeten betalen.

De regeling van artikel 5 lid 8 (oud) SW 1956 is vervallen omdat, net als dat in het Vlaams Gewest het geval is, van deze techniek veelvuldig gebruik werd gemaakt in combinatie met ANBI's. De ANBI werd benoemd tot enig erfgenaam onder de verplichting om aan een verwant van de testateur een zodanig bedrag uit te keren dat die verwant (als legataris) na betaling van de door hem verschuldigde erfbelasting hetzelfde zou overhouden als in het geval hij enig erfgenaam zou zijn geweest. De wetswijziging is in 2006 ingevoerd, omdat in dat jaar verkrijgingen door ANBI's volledig werden vrijgesteld van schenk- en erfbelasting.

Met het vervallen van artikel 5 lid 8 (oud) SW 1956 dient de eveneens geschonken schenk- en erfbelasting gebruteerd te worden. Dat dit tot ingewikkelde berekeningen kan leiden, heeft de wetgever er niet van weerhouden de regeling te schrappen. Met de huidige rekensoftware moest het volgens de wetgever mogelijk zijn de door de verkrijger verschuldigde belasting te berekenen. 22

\section{Afsluiting}

Mede als gevolg van de andacht voor het boek van Piketty staan fiscale planningstechnieken in zowel Nederland als België in het voetlicht. Nederlandse politieke partijen blijken wat de schenk- en erfbelasting betreft uiteenlopende ideeën te hebben. Ze variëren van het verhogen van de tarieven tot juist het volledig afschaffen daarvan. Dat vermogensongelijkheid wordt bevorderd door vermogensoverdracht tussen generaties wordt niet bevestigd door de notitie van het CPB. Uit deze notitie blijkt dat de vermogensongelijkheid in de periode 2007-2015 gelijk is gebleven, en dat daarbij de waardedaling van huizen een belangrijke rol heeft gespeeld.

De Vlaamse fiscale decreetgever heeft in het kader van het terugdringen van fiscale planningstechnieken een nieuwe berekeningswijze voor de erfbelasting ingevoerd voor testamenten waarin een zogenoemd duolegaat is opgenomen. Voor nalatenschappen die openvallen vanaf 1 juli 2021 betekent dit dat de in deze duolegaat-testamenten benoemde goeddoelinstellingen niets meer van hun verkrijging overhouden. Ter compensatie worden de tarieven schenk- en erfbelasting van deze goeddoelorganisaties teruggebracht van $8,5 \%$ naar $0 \%$.

Bovendien is met ingang van 1 juli 2021 voorzien in een regeling die een beperkte tariefsmatiging mogelijk maakt voor de zogenoemde vriendenerfenis. Om die tegemoetkoming te kunnen benutten, moet echter aan een aantal nauw omschreven voorwaarden worden voldaan, waaronder die van een authentieke akte. Met name die laatste voorwaarde doet vanuit een kostenoogpunt de vraag rijzen in hoeverre de nieuwe regeling in de praktijk zal worden gebruikt. Het lijkt erop dat de Vlaamse fiscale decreetgever met dit gedetailleerde stukje wetgeving zijn doel voorbijschiet. 